\title{
BREVE STATUS QUAESTIONIS DE LA CIENCIA NEOTOMISTA COMO INTRODUCCIÓN CONFUSA AL SENTIDO DE SCIENTIA TOMÍSTICA: ALGUNAS APRECIACIONES HISTÓRICAS EN FILÓSOFOS DEL SIGLO XX
}

\author{
JOSÉ MARÍA FELIPE MENDOZA \\ CONICET, Mendoza - Argentina
}

\begin{abstract}
RESUMEN: El presente trabajo se desarrolla bajo una triple restricción histórica respecto de Tomás de Aquino y su noción de ciencia: se referirá a la confusión con Cayetano, al pensamiento neo-tomista del siglo xx y a una aguda divergencia respecto de esta tradición hermenéutica. De los primeros dos se hallará el desvío del planteamiento del esse tomístico al gnoseológico y lógico de la abstractio. Del último, en cambio, la necesidad de recuperar el origen de la ciencia en el Aquiante.
\end{abstract}

PALABRAS CLAVE: Cayetano, Tomás de Aquino, Abstracción, Ciencia

\section{A summary of neo-thomistic Science like an confused Introduction to the sense of thomistic Science: some historical Appreciations in Philosophers of XX Century}

ABSTRACT: This paper develops a triple restriction on Thomas Aquinas and his notion of science: it's going to refer to the confusion between Cajetan and Aquinas, and thought's neo-Thomist of the twentieth century and a sharp divergence from the hermeneutic tradition. In the first two are the diversion of Thomistic approach to be epistemological abstraction. Of the latter, the need to recover the origin of science in the Aquiante.

KEY WORDS: Cayetano, Thomas Aquinas, Abstraction, Science

Parece que la marca indeleble con la cual el excelentísimo Cayetano ha moldeado el desarrollo del tomismo en torno a la ciencia, condujo a creer al menos durante tres siglos que la hermenéutica más apropiada para leer al mismo Tomás de Aquino venía de aquella pluma. El mismo Maritain ya había dicho que «en verdad, hay aquí una simple diferencia de vocabulario [con Tomás de Aquino], no de doctrina [con Cayetano] $»^{1}$. Mas, el Gaeta no es el Aquinate, sino un cualificado intérprete que colaboró en la difusión y expansión de la doctrina tomística². Con todo, si por doctrina se entiende, de modo analítico, el contenido de la ciencia, entonces, los principios de la doctrina son los principios de la

\footnotetext{
1 Maritain, J., Filosofía de la naturaleza, Club de Lectores, Buenos Aires, 1967. p. 29.

2 Cada uno de los filósofos que se citarán se han declarado de diversas formas continuadores del pensamiento del Aquinate. No se valoran las doctrinas de cada uno de ellos en sí mismas sino en su relación con la doctrina de Tomás de Aquino en lo concerniente a su comprensión de la ciencia, destacando la vinculación de aquellos con Cayetano.
} 
ciencia, y con ello, las diferencias doctrinales vienen a ser también diferencias epistémicas.

En este sentido conviene asimismo recordar que la historia del tomismo puede comprenderse de dos modos diversos. Primero, saber quién fue el Aquinatense y con la intención de aprender su forma mentis penetrar en su doctrina; segundo, avanzar lentamente desde Tomás hacia sus intérpretes, haciendo descansar en última instancia las personales conclusiones más en el esclarecimiento de aquellos que lo han leído que en la personal lectura de tales textos latinos ${ }^{3}$. Tal actitud, lejos de Cayetano y el mismo Tomás, conduciría finalmente a análisis tomistas que poco tienen que ver con el dominico del s. XIII y más se acercan al dominico del s. xv, quién no porque esa fuera su intención, los posteriores estudiosos de Tomás de Aquino fueron conviniendo en recurrir a su palabra como la más autorizada en el sentido de identificación o reemplazo de los textos del de Aquino. Gilson advirtió la diferencia entre ambos y con claro propósito de salvaguardar la doctrina tomística llamó a Cayetano corruptorium Thomae .

Sirva ello como introducción para señalar que tal identificación entre ambos dominicos sería el origen de que muchos de los comentadores del siglo xx, cuando recurrieron a Tomás y a Cayetano, como su eminente comentador, creyeron entender a aquél con pureza intencional, aunque lograron sólo de hecho que éste se hubiera convertido en el lente adecuado para interpretarlo. Ahora bien, no interesan aquí tanto las diferencias entre ambos teólogos cuanto el devenir de cierta fusión de sus pensamientos en relación con el descuido de la noción de ciencia en Tomás de Aquino.

Por lo tanto en este trabajo se considerará aquella franja temporal de análisis sobre el tópico de la ciencia que se ciñe a neo-tomistas del s. xx y que interpretaron a Tomás de Aquino desde alguna alusión a Cayetano. En correspondencia con ello se busca poner en evidencia un oscurecimiento histórico de la doctrina tomística y no tratar en profundidad lo que efectivamente Tomás sí afirmó textualmente acerca de la ciencia.

1. Tomismo del Siglo XX: LA PONDERAción de CaYetano y Aristóteles Sobre Tomás de Aquino. Un desvío históRIco

A modo de primera aclaración conviene volver a considerar que después del fallecimiento del Aquinate fue configurándose una tradición peculiar cada vez más ajena, no tanto según su intención, pero sí según su pensar, a

\footnotetext{
3 Gilson, E., El filósofo y la teología, Guadarrama, Madrid, 1962. p. 253.

4 Gilson, E., "Cajetan et l'humanisme théologique», AHDLMA, 22 (1955) 113-136. pp. 136.
} 
la doctrina tomística en general. Dicha peculiaridad, tal vez más epocal ${ }^{5}$ que personal, puede ceñirse en lo esencial a las palabras de García Cuadrado:

Las grandes sistematizaciones de los maestros medievales habían cedido paulatinamente el puesto a la lógica nominalista. La escolástica iba degenerando cada vez más en unos tratados dialécticos farragosos e inútiles ${ }^{6}$.

Esta mencionada razón de la diferencia entre Tomás de Aquino y su escuela afincó en un giro epocal cuyo epicentro fue una crisis antropo-teológica que se tradujo en un avance del nominalismo y la lógica sobre la metafísica ${ }^{7}$. La impronta de la escuela tomista concebida bajo la égida del nominalismo, con consciencia de fidelidad a Tomás de Aquino, fue alterando a la vez que solidificándose en numerosos pensamientos que al presente la diferencia se ha mostrado como fundamental.

Con todo, una primera aproximación a la historia del tomismo muestra que son innúmeros los estudios acerca de la doctrina del Aquinate principalmente desde la conquista del Gaeta en reemplazo de las Sentencias de Pedro Lombardo. Pues la difusión de los textos tomasianos encontró en la Época Moderna ${ }^{8}$ tres interpretaciones eminentes: el mismo Cayetano, Fancisco Silvestere de Ferrara y Juan de Santo Tomás9. Sus esfuerzos por defender y clarificar la glosa

5 Gilson, E., T. Langan, Filosofía Moderna, Emecé, Barcelona, 1967. p. 13: «Ya desde la muerte de Occam, el escolasticismo se había consumido, agotándose en interminables sutilezas y en ásperas controversias entre sus Escuelas. Albertistas, tomistas, escotistas, occamistas, averroístas [...] todos se afanaban en vencer y acallar a todos los demás; y mientras cada facción confiaba en ser la que, por fin, ganaría la batalla, el escolasticismo continuaba su agotamiento, hasta desaparecer. Pero no fue la filosofía moderna quién la mató, pues cuando ésta surgió, ya hacía tiempo que el escolasticismo había muerto».

6 García Cuadrado, J. A., La luz del intelecto agente. Estudio desde la metafísica de Bañez, Eunsa, Pamplona, 1998. p. 23.

7 Fabro, C., Historia de la Filosofía I, Rialp, Madrid, 1965. pp. 559-560: «El triunfo del nominalismo ocamista, que había caracterizado el último período de la primera Escolástica, había reducido la filosofía a pura lógica y dejado a la Revelación cristiana los problemas acerca de la naturaleza del alma humana y de la existencia y naturaleza de Dios [...] La Segunda Escolástica nació señalada con los estigmas de la decadencia de la primera».

8 Para un panorama científico general que explica sumariamente las diferencias entre las concepciones clásica-griega, clásica-medieval y moderna, cfr: SANGUINETti, J. J., Ciencia y Modernidad, Lohlé, Buenos Aires, 1988. pp. 47-60: El análisis científico no tiene en cuenta como tópico una cuestión gnoseológica sino metafísico teleológica. Procede en la explicación clásica de la ciencia con el ejemplo de Tomás de Aquino insistiendo en el carácter de necesidad, el fin y las causas como nota constitutiva diferencial entre las ciencias de dos épocas: la medieval y la moderna.

9 Fabro, C., Introducción al Tomismo, Rialp, Pamplona, 1967. pp. 153-154: «La gran vuelta al tomismo tiene dos centros de expansión, Italia y España; son considerados como los mejores tomistas italianos el cardenal Gaetano, Francisco Silvestre de Ferrara, etc. En España, F. De Vitoria, D. Bañez y Juan de Santo Tomás». 
tomasiana los llevó a una sistematización de su pensar diversa de la que el mismo Tomás había concebido ${ }^{10}$.

Tal es la compenetración de estas tres doctrinas en dicha historia, y principalmente con Cayetano ${ }^{11}$, que ahora resulta evidente que esta superposición supone confusión en al menos dos sentidos: las interpretaciones del Gaeta clarifican con verdad el pensamiento de Tomás ${ }^{12}$ y/o el Aquinate no puede leerse sino a través de un camino ascendente hacia su doctrina a través principalmente de estos autores.

Entre los comentadores que promueven una lectura de un núcleo esencial de un tomismo intencionalmente puro, y que por lo mismo, en algún momento deberían detenerse en la noción de ciencia, - término que puebla casi, sino todos los textos tomísticos-, pueden mencionarse, en el devenir del siglo xx, a una serie de filósofos representativos de una época que comulga con una hermenéutica cayetanista y/o aristotélica para explicar a Tomás de Aquino ${ }^{13}$.

Manser por ejemplo, afirmó en su obra La esencia del Tomismo que «es bastante corriente que se acentúe la influencia aristotélica en las doctrinas del tomismo [...]. Por eso, a la tendencia filosófica del Aquinate en el siglo XIII se la denomina también, sencillamente, aristotélica» ${ }^{14}$; o bien la siguiente afirmación: «en el desarrollo y perfeccionamiento, rigurosamente lógicos y consecuentes, de la doctrina aristotélica del acto y la potencia vemos nosotros la más íntima esencia y el punto central del tomismo» ${ }^{15}$. Su

10 FABro, C., Historia de la... p. 562: «[Cayetano y Silvestre de Ferrara] Con frecuencia los principios fundamentales de la gnoseología y la metafísica (de Tomás de Aquino) fueron sofocados por largas discusiones de tipo teológico». Cfr: C. FABro, La Nozione Metafisica di partecipazione: secondo $S$. Tommaso d'Aquino, $2^{\circ}$ ed. revisada y aumentada, Societá Editrice Internazionale, Torino, 1950. p. 188: «Existe una diferencia real entre la noción tomista tradicional de Ente y aquella propuesta por Cayetano y conservada por la mayor parte de los tomistas modernos».

11 García CuAdrado, J. A., La luz del intelecto agente... p. 20: «La historia crítica del tomismo ha mostrado cada vez con mayor claridad de qué manera la doctrina del Doctor Angélico ha sufrido síntesis empobrecedoras e interpretaciones desafortunadas precisamente de aquellos mismos que enarbolaban la bandera de la fidelidad al pensamiento tomista. A lo largo de este siglo Fabro y Gilson principalmente han mostrado de qué manera las principales tesis metafísicas tomistas se han desvirtuado en gran parte por las interpretaciones de sus comentadores: Capreolo, Cayetano, Silvestre de Ferrara, etc».

12 Véase ilustrativamente esta cuestión en la edición definitiva leonina de los textos tomasinos.

13 FABro, C., Historia de la... p. 562: «Como comentaristas de Santo Tomás, Cayetano fue más ardiente, original y polémico; el Ferrariense más sujeto al texto, más fiel y moderado. Sustancialmente, es claro, siguieron el pensamiento tomista; se apartan de él en algunos puntos particulares. Ello demuestra que los comentaristas no lograron una visión clara y límpida de las líneas maestras de la síntesis filosófica de Santo Tomás».

14 Manser, G. M., La esencia del Tomismo, CSIC, Instituto de Investigación Luis Vives de Filosofía, Madrid, 1947. p. 102.

15 Manser, G. M., La esencia..., p. 104. 
dependencia de Cayetano en reemplazo del mismo Aquinate en cuestiones como el problema de los trascendentales o la analogía es también evidente ${ }^{16}$.

Por su parte, el pensamiento de Garrigou-Lagrange, claramente distintivo de una tradición interpretativa moderna de Tomás, en su obra La síntesis tomista, no sólo concibe la doctrina del Angélico como aristotélico-tomista ${ }^{17}$, sino que la entiende y explica directamente a través de los fieles intérpretes de la segunda escolástica ${ }^{18}$, los documentos papales, las 24 tesis tomistas y como la única filosofía del sentido común en oposición al molinismo, escotismo y suarismo entre otros ${ }^{19}$.

16 Manser, G. M., La esencia...: Entre los principales intérpretes de Tomás de Aquino aparece Cayetano. En orden a la fundamentación y explicación correcta tomasiana del origen del conocimiento humano pueblan las notas cayetanistas y su sentido hermenéutico. En apoyo de Tomás de Aquino como su natural continuador, quien en ocasiones lo reemplaza, pueden citarse los siguientes temas: El problema de los universales (p. 266); las ideas trascendentales y la primacía noética del ser (pp. 291-295, 302-303); las pruebas de la existencia de Dios (p. 394); el amplio espectro de la analogía (pp. 435-438, 471-478 y ss.); el problema del esse y la essentia (p. 600); o bien, el principio de individuación (pp. 739, 765 y ss.)

17 Garrigou-Lagrange, R., La sintesis tomista, Dedebec, Buenos Aires, 1946. p. 74: «Esta síntesis metafísica realizada por Santo Tomás es mucho más perfecta que la doctrina explícitamente profesada por Aristóteles; pero desde el punto de vista filosófico es el desarrollo de los principios formulados por el Estagirita. Se puede decir que es la misma filosofía, pero llegada a la edad madura». Es notable la fusión entre las filosofías de Tomás y Aristóteles sobre todo en el apartado "conclusión» (pp. 409-427) bajo la expresión constante de filosofía aristotélico-tomista. En ella se lleva a cabo una defensa o apología de este modo de proceder en contra de las diferentes formas del pensar contemporáneo y moderno, ya sean Husserl, Hartmann, Kant, Hegel, etc.

18 Garrigou-Lagrange, R., La síntesis...: La influencia de Cayetano puede verse por ejemplo en la explicación de la analogía (p. 111); la identificación y distinción real en Dios de sus atributos, es decir, formaliter eminenter (pp. 114-115); la comunicabilidad e incomunicabilidad entre las Personas Divinas (p. 116); la demostración tomista de la tradición y no tomística de Tomás de Aquino de la doctrina de los grados de abstracción (pp. 207-208); el problema de la unidad del hombre (212, 214); Dios como bien universal (p. 317); o en relación con, por ejemplo, la virtud infusa de la caridad y el fin del hombre (p. 403). Agréguese a ello: «El mérito de Cayetano consiste en haber reconocido la verdadera grandeza de Santo Tomás del cual sólo ha querido ser el fiel comentador» (p. 443). «La doctrina formulada por Cayetano no sólo es la única conforme con Santo Tomás, sino que también es la única conforme con la noción que la razón natural o sentido común se forma de la persona y de los pronombres personales, yo, tu, él, como sujeto inteligente y libre» (p. 492). Véase asimismo el planteo, continuación y defensa de la segunda escolástica respecto de la filosofía del Aquinate en donde explícitamente se escriben los siguiente nombres: Cayetano, Capreolo, el Ferrariense y Juan de Santo Tomás (pp. 487-494).

19 Garrigou-Lagrange, R., La sintesis... Esta actitud aparece plasmada a lo largo de todo el texto, a veces defendiendo la doctrina tomista, a veces marcando las diferencias y los errores de las filosofías de Duns Scoto, Suárez, etc. 
Engrosan esta lista, por la época de sus escritos y la influencia de Cayetano, Grabmann $^{20}$, Sertillanges ${ }^{21}$ o Weber ${ }^{22}$. El segundo de ellos expone su principal síntesis de esta doctrina en su obra "Santo Tomás de Aquino». Como en el caso de los anteriores, recurre también a Cayetano para echar luz sobre algunos puntos cruciales de la doctrina tomística, como por ejemplo las cuestiones de la analogía o la abstracción.

Dietrich Lorenz, si bien ocupado en describir la tradición de la metafísica tomista, y no en una historia de los disensos de la expresión «ciencia» en la misma tradición, menciona escuetamente tres etapas y advierte la importancia de estudiarla, no de acuerdo a una perspectiva apologista, sino más bien, histórica ${ }^{23}$. Reúne en este artículo bajo el apartado «Tradición» tres generaciones neo-tomistas. La primera o clásica arraigada a comienzos del s. xx, cuya exégesis está regida bajo la profunda influencia de Cayetano y Juan de Santo Tomás, además de sostener de diversas maneras una suerte de plena conformidad con la doctrina de Aristóteles. Entre estos autores menciona al mismo Manser, Mandonnet, Gardeil y Giacon, presentando como una excepción epocal a Garrigou-Lagrange en tanto que veía en Tomás lo que hoy es imprescindible, que su filosofía es una filosofía del ser $^{24}$.

Pese al esquema de Lorenz, vése aquí la profunda influencia de la segunda escolástica aún presente en numerosos intérpretes del Aquinate, siendo ejemplos de ello Derisi ${ }^{25}$ o el afamado defensor en tiempos contemporáneos de la

20 Grabmann, M., Santo Tomás de Aquino, Labor, Madrid, 1945. p. 160: «Para restablecer la inteligencia de diversas doctrinas tomistas, discutidas a causa de la dificultad o el laconismo del texto, se podrá recurrir no sin provecho a los discípulos inmediatos o mediatos de Tomás».

21 Sertillanges, A. D., Santo Tomás de Aquino, t. II, Dedebec, Buenos Aires, 1945: La amplitud con la que cita a Cayetano consintiendo en sus explicaciones mezclando en un todo ambas doctrinas se observa en: la génesis del alma (p. 163); el esquema de conocimiento tomista (p. 174); abstracción y memoria (p. 179); el juicio como segunda operación de la razón (p. 183); el querer volitivo (pp. 214, 216); el libre albedrío y la felicidad (p. 263); la acción humana y el deleite (pp. 326, 331).

22 Weber, P. J., Santo Tomás de Aquino. El genio del orden, Poblet, Buenos Aires, 1949: Es un texto de escasas notas a pie de página que, con aparente fidelidad al Aquinate, desarrolla una serie de tesis esenciales. La presencia probable de Cayetano se deja adivinar principalmente en la temática de los grados de abstracción (pp. 170-178). Se rescata sin embargo el reconocimiento de la influencia neoplatónica en los textos del Angélico (pp. 142, 180-181); un esbozo del orden de las ciencias físicas en Tomás (pp. 124-125); y un estudio del proceder aquinatense a través de principios filosóficos-científicos orientativos para comprender su tendencia a ordenar cualquiera forma de saber (pp. 90-116).

23 LOREnZ, D., «Sobre algunos disensos, progresos y crisis en la historia de la metafísica tomista», en: Revista Philosophica 26, (2003), Instituto de Filosofía Pontificia Universidad Católica de Valparaiso, pp. 1-16. (p. 11)

24 LoRenz, D., «Sobre algunos disensos...» (pp. 4-5)

25 Seguidor de las doctrinas de Cayetano, cfr: Derisi, O. N., Esbozo de una epistemología tomista, Cursos de cultura católica, Buenos Aires, 1946: En relación con los grados de abstracción (pp. 99-101); cfr: DeRISI, O. N., La doctrina de la inteligencia de Aristóteles a Tomás de Aquino, Club de Lectores, Buenos Aires, 1980: Heredero de una interpretación moderna de 
filosofía tomista J. Maritain ${ }^{26}$. Si bien ambos se entienden como seguidores de Cayetano, Maritain se introduce en los problemas científicos contemporáneos. En virtud de esto, el filósofo francés marca una real diferencia en relación con los demás intérpretes, puesto que, preocupado de la situación actual de las ciencias, las estudia, critica, encausa y corrige desde aquella tradición heredada. Baste por el momento mencionar su siguiente afirmación:

Es mérito de santo Tomás y de sus grandes comentaristas haber formulado con claridad y resueltamente el problema del conocimiento...y no sólo haberlo planteado, sino también haberle dado la solución más profunda ${ }^{27}$.

Puede verse, luego de este breve recorrido, que el estudio de la ciencia en Tomás de Aquino como trasfondo de dichos planteos se ha dispersado en temas singulares que hacen a la scientia tomística pero que no la abordarían exactamente en su completitud y orientación. Un sugerente ejemplo de la paradoja de la reducción de la ciencia a su método, —que en este caso sería principalmente la abstractio-, y de la confusión, en medio de la recurrencia a Cayetano o Juan de Santo Tomás, entre los ámbitos de la gnoseología con la realidad fáctica del ser del ente, se observaría en Santiago Ramirez. Tal estudioso recurre a una clasificación de las ciencias desde una perspectiva lógica y sostiene expresamente que los intérpretes tomistas profundizan la doctrina del Aquinte ${ }^{28}$. Sería también el caso, además de los autores anteriormente mencionados, de Vicente-Burgoa ${ }^{29}$.

Santo Tomás, apologeta de su doctrina y defensor de una visón aristotélica-tomista (Prólogo, Introducción, pp. 30; 31; 32, y gráficamente las pp. 160; 161; 177), seguidor de Cayetano en los grados de abstracción (p. 36); en la espiritualidad e inmaterialidad de la inteligencia (p. 66); y la explicación de las relaciones entre ser y ente (p. 89) o también, respecto de Juan de Santo Tomás, la exposición de algunos aspectos en torno al acto de inteligir como diferente del representar (pp. 202-204).

26 Las influencias positivas de Cayetano y Juan de Santo Tomás en, cfr: Maritain, J., Ciencia y filosofía, Taurus, Madrid, 1958: Los grados de abstracción cayetanistas, las divisiones de la ciencia según la lógica, las diferencias entre ciencia y sabiduría (pp. 185; 193-195; 198-206; 211-225); cfr: Maritain, J., Ciencia y Sabiduría, Debec, Buenos Aires, 1944: Las citas de Cayetano guardan relación con los sentidos de ciencia (pp. 28-29); la diferencia entre teología y metafísica (pp. 42-45); los grados de abstracción formal (p.69-71); la división de las ciencias según la lógica y su definición (pp. 73-74; 80); la iluminación en santo Tomás desde Cayetano y Juan de santo Tomás (pp. 94-97); cfr: Maritain, J., Filosofía de la...: Formulación explícita de la diferencia de los grados de abstracción cayetanista (pp. 24-25) atribuida al medioevo escolástico (pp. 28).

${ }_{27}$ Maritain, J., Los grados del Saber, Club de Lectores, Buenos Aires, 1978. pp. 183.

28 Ramirez, J. M., De ipsa philosophia, Instituto de filosofía Luis Vives, Madrid, 1970. p. 168.

29 Vicente-BurgoA, L., «La abstracción científica en el pensamiento maduro de Tomás de Aquino (o en torno a la última destrucción de la metafísica tomista)», en: Estudios Filosóficos LVII, (2008). pp. 61-100: Este autor se inscribe en la tradición neo-tomista bajo ciertos aspectos: en primer lugar considera que Tomás de Aquino es plenamente aristotélico "aunque tomando del platonismo y del neoplatonismo ciertos elementos complementarios, en cuanto contribuyen a una mejor comprensión de lo real y no choquen entre sí (p. 62)». 
Conforme lo precedente puede decirse que se muestra efectivamente persuasiva la lectura de la escuela tomista que se orientaría en torno a la problemática científica en una dirección no tomística y que privilegiaría como elementos esenciales sin unidad con y sin un estudio profundo de su noción de ciencia los puntos metódicos de abstracción ${ }^{30}$ y analogía ${ }^{31}$. Tales consideraciones, conviene ahora aclarar, parecen pivotar sobre una antropología dudosamente tomística porque estaría enraizada, según sus planteamientos, en una matriz moderna, lo cual en parte ya ha querido ser mostrado. En este sentido, cada uno de estos puntos pertinentes a la ciencia han sido, en verdad, profundizados hasta ver en ellos el núcleo de la auténtica scientia en el Aquinate y, mirando desde ellos, se habrían descuidado otros ítems científicos como las causas de los entes y sus principios.

«[...] en cuanto que los saberes teóricos o especulativos se diferencian y construyen a base de la abstracción formal que depara el objeto propio de cada ciencia (pp. 85-86)» «[...] y con ello, que las ciencias especulativas se diferencian lógicamente por el objeto que especulan (p. 86)» «y que la abstracción formal es el fundamento de cada saber especulativo afirmándolo no sólo del Aquinate sino también de toda la tradición neo-tomista (pp. 86-87)». Las cursivas son mías.

30 Lertora Mendoza, C. A., Tomás de Aquino. Teoría de la ciencia, Ediciones del Rey, Buenos Aires, 1991. p. 8: «En cuanto a Santo Tomás generalmente se acepta que su teoría de la ciencia depende fundamentalmente de su concepción de los grados de abstracción de tal modo que los mismos textos del comentario a Boecio constituyen una teoría gnoseológica general y una teoría de la ciencia en particular. En esta postura se sitúan la mayoría de los tomistas antiguos y modernos». Existen numerosos estudios específicos sobre el tema de la abstracción que no he querido incluir por no ser la dirección ab initio escogida. Entre los autores que sostienen una interpretación tomista acompañada de la tradición escolástica moderna se pueden citar, además de los mencionados en el cuerpo del trabajo a: E. D. SIMMONS, «In Defense of Total and Formal Abstraction», en: New Scholasticism 29 (1955) 427440; Lopez SALGado, C., "Abstractio y Separatio como acceso a la metafísica», en: Sapientia 19 (1964) 102-116; Ponferrada, G. E., «Nota Sobre Los grados de Abstracción», en: Sapientia 33 (1978) 267-284 y Pasnau, R., "Abstract Truth in Thomas Aquinas» en: Lagerhund, H. (ed.), Representations and Objects of Thought in Medieval Philosophy, Hapshire, Burlington 2007, 33-61. En cambio, entre los autores tomísticos a: Kockelmans, J., The Metaphysics of Aquinas: A Systematic Presentation, Bibliotheek van de Faculteit Godgeleerdheid, Louven, 2001; Llano FuENTES, C., Abstractio, bases noéticas para una metafísica no racionalista, Universidad Panamericana, México D. F, 2001. Una introducción a la diferente interpretación entre Tomás de Aquino y Cayetano respecto de la noción de abstracción, cfr: CuccIA, E. J., "Una controversia acerca del sentido de la abstracción», en: FiLIPPI, S. (ed.), Controversias Filosóficas, Científicas y Teológicas en el Pensamiento Tardo-Antiguo y Medieval, Paideia, Universidad Nacional de Rosario, Facultad de Humanidades y Artes, 2011.pp. 273-281: «La consideración que hace Tomás de Aquino de la abstracción posee una naturaleza íntimamente ontológica ya que la determinación de la abstracción se hace en razón de qué sea realmente conocido, si sustancia o accidente [...] En cambio la abstracción formal se encuentra inmersa en un ámbito lógico u objetivo, en el cual las distinciones en el ser del objeto se originan en el diverso modo de considerar una misma realidad conocida» (p. 278).

31 Maritain, J., Filosofía de la... p. 36: La división de las ciencias según los grados de abstracción formal (científica) tienen base en la comprensión de la palabra «ser» interpretada analógicamente. Cfr: Gambra, J. M., La analogía en general. Síntesis tomista de Santiago Ramirez, Eunsa, Pamplona, 2002. 
A modo de recapitulación, y según esta situación de conciencia de fidelidad a Tomás de Aquino, aunque desvirtuaría o volvería dudosa la orientación impresa por el mismo Aquinate a sus escritos de índole científica, se pueden mencionar a los siguientes historiadores, apologistas ${ }^{32}$ y filósofos de una doctrina tomista que en numerosas cuestiones siguen el pensamiento del cardenal Cayetano: Mandonnet, Manser, Grabmann, Sertillanges, Garrigou-Lagrange, Gardeil, Giacon, Derisi, Maritain, Ramirez, Weber o Vicente-Burgoa. Pueden añadirse además, Jesús García Lopez ${ }^{33}$ o Mauricio Beuchot. Este último, en su texto Introducción a la Filosofía de Santo Tomás de Aquino, dedica un capítulo a la ciencia tomista ${ }^{34}$. En dicho apartado se pueden observar algunas irregularidades o ambivalencias como la utilización de la expresión denunciada anteriormente de filosofía aristotélico-tomista o el surgimiento de la lógica y la metafísica del mismo grado de abstracción.

Mas, si se atiende a aquellos títulos que deberían ceñirse a lo que anuncian, se descubre con sorpresa una situación similar a la precedente. Celina Lertora Mendoza por ejemplo, bajo el título Tomás de Aquino. Teoría de la ciencia,

32 Respecto de esta situación puede decirse lo siguiente: Es notable que la así llamada escuela tomista asumió un Tomás de Aquino que se estudiaba para dar respuestas a cuestiones muy diferentes de las del Angélico, con la intención no tanto de considerar su doctrina en sí misma, sino de utilizarla como elemento dialéctico, ya sea a la ofensiva como es el caso de Cayetano contra los escotistas, o a la defensiva, - situación relativamente actual de filósofos que hacen cierta apología de Tomás de Aquino-. Se logró así en cierto sentido que se anquilosara su doctrina y se corriera el riesgo de desvirtuarla en pos de un tomismo puro, puesto que se exaltaba más a un Tomás que era un gran filósofo que su contenido doctrinal.

33 García Lopez, J., Estudios de metafísica tomista, Eunsa, Pamplona, 1976: Es un libro enmarcado claramente en la tradición tomista en la que convive también una apertura a la influencia de San Agustín. Las citas por ejemplo de S. Ramirez suelen aparecer junto con las de Cayetano. Del Gaeta, como intérprete del Aquinate, véase la abstracción de los contenidos sensibles (p.18); la explicación de la diferencia entre abstracción total y formal (pp.21-24); los grados de abstracción formal (pp. 24-28); la división en el tercer grado de abstracción entre metafísica y lógica (p. 26). Respecto de la analogía: la diferencia entre identidad, semejanza e igualdad, principalmente esta última (p. 35); de la diferencia entre analogía real y lógica (p. 44); nuevamente entre abstracción total y formal (p. 59); las dos direcciones históricas de Cayetano y Suárez respecto de la significación de la analogía de proporcionalidad propia en la que se defiende por peso de la historia y la autoridad humana la posición interpretativa del primero, aunque se advierte la corrección de S. Ramirez en ese punto (pp. 71-78); la explicación del proceder del entendimiento humano respecto del yo o ser inteligible en potencia (p. 241); la recomendación de la lectura del De ente et essentia de Cayetano para esclarecer qué significa que «el objeto propio e inmediato de nuestro entendimiento es el ente concretado en la actualidad sensible» (p. 249); y véase también ocasionalmente la influencia de Juan de Santo Tomás en, por ejemplo, la analogía de proporcionalidad (p. 78) o de Juan Capreolo respecto de la simple aprehensión (p. 210).

34 Bеuснот, M., Introducción a la filosofía de Santo Tomás de Aquino, San Esteban, Salamanca, 2004: Esta obra en el capítulo «La filosofía y la ciencia» (pp. 29-52) comete ciertos deslices. No diferencia y vuelve ambigua la distinción entre abstracción y separación en relación con la metafísica (p. 45); atribuye al mismo grado de abstracción la lógica y la metafísica (p. 45) y afirma a la ciencia ética como ciencia teórica (p. 45), además de agregarse una atmósfera lógica - y no metafísica y física- de explicar las relaciones entre las ciencias. 
aceptando aquella tradición sin discutirla, entiende sin embargo que la ciencia y su clasificación en Tomás de Aquino depende de la teoría de los grados de abstracción como su justificación ${ }^{35}$.

Juan José Sanguineti por su parte, escribió una obra consagrada a la ciencia tomística titulada La filosofía de la ciencia según Santo Tomás ${ }^{36}$. Tal escrito, habiendo buscado mantenerse en los límites de un tomismo puro, parecería haberse desarrollado bajo una perspectiva gnoseológica descuidando el factum de las sustancias y manteniendo por tanto en el libro una lógica ambivalente. Aparecería en ello el inconveniente de explicar las relaciones entre las ciencias desde la misma metafísica, convirtiéndose así dicho estudio en un texto que distinguiría nominalmente las ciencias entre sí, pero que in concreto no lograría advertir la honda realidad de las sustancias sensibles.

35 Lertora Mendoza, C. A., Tomás de Aquino... p. 14: «En el Comentario a Boecio, la teoría de los grados de abstracción se presenta como una justificación y explicación de la división de las ciencias especulativas, actitud que Santo Tomás mantiene el comienzo del Comentario al primer libro de la física aristotélica».

36 Sanguinetti, J. J., La filosofía de la ciencia según Santo Tomás, Eunsa, Pamplona, 1977: Esta es la única obra, a diferencia de la de Lertora Mendoza, que se detiene propiamente en la noción tomística de ciencia. Si bien tiene muchos aspectos destacables, como la corrección de Maritain cuando éste desvirtúa textos tomísticos (p. 75), conviene ante todo señalar algunos de los puntos cuestionables. La perspectiva gnoseológica y metafísica del texto se advierte anticipadamente en su índice y se confirma conforme transcurren los capítulos. La tendencia a la explicación metafísica de todas las ciencias encuentra cauce en la dependencia de los principios de las ciencias particulares de la ciencia universal. La importancia de las causas segundas está no tanto en ser causas próximas y primeras de los seres naturales cuanto en mostrar la vinculación con la metafísica. Mas, si se atiende propiamente a los aspectos gnoseológicos de la obra, puede percibirse la simultaneidad en el hombre de ser y saber hasta opacar el ser y destacar el saber. Con todo, la preferencia del saber por sobre el ser de las sustancias quiere señalar que en el saber ya hay ser, aunque se corra el riesgo de identificar el saber con el ser en las explicaciones científicas. Esta sutil cuestión, bien mirada, culmina en la justificación de la división de las ciencias desde la gnoseología y la lógica, pero no primeramente por el ser sustancial. Pese a esto, el mismo texto menciona la real diferencia entre el ser y el saber, y destaca principialmente que el conocimiento depende de y se apoya en el ser, advirtiendo contra la identificación de la filosofía con la Física, la Lógica (p. 93) o la Matemática (p. 98) como reemplazo de la Metafísica en tanto Filosofía Primera. Apoya en el intelecto y no en el esse la distinción entre separatio y abstractio, aplicando la primera a la Metafísica y la segunda a las ciencias particulares, - la segunda, efectivamente, se apoya sobre el intelecto- (p. 135) y por ello, como consecuencia, se verá que la metafísica procede por separación mental (p. 147) obteniendo de este modo un objeto real llamado separado real (p. 137). Utiliza positivamente las denominaciones cayetanistas y no tomísticas de abstractio totius y abstractio formalis (pp. 150-154). Una última corrección puede hacerse a esta obra. Varios de los textos utilizados son hoy en día dudosos o falsos. Ellos son De principio individuationis, De instantibus, De natura generis, De demostratione, De fallaciis. Injustas, por lo demás, son las críticas dirigidas a esta obra por parte de, Cfr: REGo, J. C., «A propósito del orden tomista de las ciencias según Juan José Sanguineti», en: Boletín de Ciencias Políticas y Sociales, U. N. Cuyo, Fac. de Ciencias Políticas y Sociales, Mendoza, Argentina, 24, (1979), pp. 211-217: Tales críticas son dirigidas desde S. Ramirez en relación con el término abstracción. 
Por lo tanto, pudiera primeramente concluirse que estas apreciaciones históricas han intentado mostrar la ausencia de estudios acerca del sentido de la noción de ciencia en Tomás y el consiguiente desvío a planteos gnoseológicos, válidos por sí mismos, pero no idénticos al esclarecimiento del quehacer científico, sus fines y causas. Y así, la identidad entre doctrina y ciencia como juicio previo y la comprensión de la misma desde operaciones mentales parecen haber desembocado en planteos en donde exponer acerca de la ciencia era hacerlo mediante la mención de qué sea aquello de abstracción.

En otras palabras, tal cuestión en el presente señalaría que entender acerca de la ciencia no sería otra cosa que comprender los grados de abstracción especulados por Tomás de Vio. A su vez, esta simbiosis resultante ha devenido principalmente en una forma falsa de comprensión, a saber: ciencia y abstracción se identificarían en el hecho de señalar a la abstracción como el centro desde donde se explicaría adecuadamente la ciencia en Tomás de Aquino, cuando tal término, la abstractio, sin que se le reste importancia, quedaría secundado al privilegiar primeramente las causas de los entes en sí, razón de ser de los seres sustanciales.

\section{CONTRASTACiÓN: LAS BASES DE UN CAMINO DIVERSO EN LA HiSTORIA DEL TOMISMO}

En la historia del tomismo no todas las voces han hablado unidireccionalmente. Existen diferencias profundas entre los declarados continuadores de Tomás vía Cayetano y quienes denuncian las diferencias entre ambos filósofos.

Si se continúa con el esquema de Lorenz, puede advertirse que la historia del tomismo comienza a bifurcarse, según su juicio, en dos caminos. Uno de ellos prolonga la tradición más cayetanista; el otro, en cambio, introduce un elemento renovador que, bajo el nombre de segunda generación, comienza en los años 30'. De ella observa lo siguiente: la ruptura con el esquema interpretativo tradicional debe entenderse como la advertencia del peligro de identificar las doctrinas de Aristóteles, Tomás de Aquino ${ }^{37}$ y Cayetano. En esta época reúne personalidades como Gilson, Fabro y Geiger, autores que insistieron en la originalidad del ser tomasiano ${ }^{38}$.

37 Cfr: Sanguinetti, J. J., Ciencia aristotélica y ciencia moderna, Educa, Buenos Aires, 1991. pp. 27-123: El contenido de tales páginas presenta y sitúa históricamente la filosofía y la ciencia de Aristóteles mostrando desde una valoración del presente la importancia del Estagirita para su entonces y para el Medioevo. La fuerza e impronta de su pensamiento en la ciencia clásica aparece en ocasiones discutidas, marcando límites y asertos; en cambio, a pie de página se multiplican las citas de Tomás de Aquino insistiendo a veces en los puntos concordantes y a veces en los discordantes. Pese a esto, cabe advertir que el autor no presenta al Aquinate como un claro continuador del Estagirita.

38 Cfr: Gilson, E., «Elementos de una metafísica tomista del ser», en: Espíritu 41, (1992). 5-38. Trad. Moya Obradors, P. J.. Cfr: Del mismo traductor, «El ser en Santo Tomás de Aquino según Etienne Gilson», en: Anales de Filosofía IV, (1986). 175-186. Cfr: FaBro, C., Dall essere all esistente, Morcelliana, Brescia, 1965. p. 16: En el contexto reflexivo en torno al ser 
En este nuevo contexto aparece la posición particular de Cornelio Fabro quien colabora en la dilucidación de un tomismo verdadero y esencial. Con trazos rápidos y generales se muestra atento a no identificar la doctrina de Tomás de Aquino con las de sus comentadores, ni a juzgar apresuradamente que dicha filosofía pueda llamarse aristotélico-tomista, cuando a la par advierte sus diferencias y las influencias del neoplatonismo ${ }^{39}$.

Gilson ha escrito, por su parte, numerosos trabajos en contra de la identificación del Aquinate con Cayetano y en este sentido Bonino dice:

En efecto, sea o no debido a que Cayetano es tenido en el neotomismo por el Comentador por excelencia, aquel cuyas glosas forman un cuerpo con el texto del maestro, el hecho es que el «tomismo» de Tomás de Vio es, a los ojos de Gilson, el arquetipo de pseudotomismo y que su crítica de la escuela se concentra en la figura de Cayetano hasta el punto de que, en una carta al P. de Lubac no duda en declarar que «el celebre comentario (de Cayetano) es un corruptorium Thomae perfectamente logrado ${ }^{40}$.

En la línea de Gilson o Fabro insisten E. Alarcón y S. Gelonch. El primero, en un artículo fechado en 1992, advierte principalmente en torno a la doctrina del Aquinate, que es necesaria cierta cautela metodológica. Se corre el riesgo, nos dice Alarcón, de que «la doctrina estudiada quede sustituida por la de su intérprete, probablemente menos estimable ${ }^{41}$. Señala a su vez como elemento importante conocer a los especialistas pese a no ofrecer un criterio seguro de interpretación. Por ello sólo queda, insiste, después de hacer caso omiso de las escolásticas modernas, una sóla vía: conocer las fuentes del mismo Tomás ${ }^{42}$. Como corolario agrega que la historiografía moderna se ha centrado en aspectos más concretos del pensamiento del de Aquino confrontándolo con autores importantes de su tiempo ${ }^{43}$.

Contra aquellos autores tomistas y en relación con la presencia del Gaeta, Gelonch también ha dicho:

$\mathrm{Ni}$ los tres grados de abstracción, ni la distinción entre ens primum cognitum y el ens como objeto de la metafísica, ni todas las distinciones objetivas o del objeto en cuanto tal, ni siquiera la distinción entre una abstracción neutra

tomístico Fabro anota la actitud de apertura humana al ser en su reconocimiento como prius absolute con la consiguiente aclaración de que cualquier determinación de la experiencia como la ciencia o la técnica se fundamenta en la riqueza de la verdad del ser.

39 FABro, C., Introducción...: Véanse «Los principios doctrinales» (cap. 4) y «Líneas de desarrollo histórico» (cap. 5, pp. 92-94)

40 Bonino, S-T. (O.P), «La historiografía de la escuela tomista: El caso Gilson», en: Scripta Theologica 26 (1994/3) 955-976. p. 961.

41 Alarcón, E., «Una cuestión de método. Consideraciones previas a la interpretación de Santo Tomás de Aquino», en: Thémata. Revista de Filosofía 10, (1992), 387-401. p. 387.

42 Alarcón, E., «Una cuestión de...» p. 391.

43 Alarcón, E., «Una cuestión de...» p. 394. 
y otras total y formal son doctrinas enseñadas por el Aquinate, al menos en sus escritos ${ }^{44}$.

Conforme con los argumentos contrarios a la identificación de juicios entre ambos dominicos se corre el riesgo de creer que en la actualidad se conoce más acabadamente el pensamiento tomístico puro. Las advertencias son válidas y la dirección de los estudios ha tomado en numerosos casos la orientación de Alarcón ${ }^{45}$. Pero en la situación concreta de la ciencia en el Aquinate las advertencias existen aunque los textos que traten especulativamente dicha temática escaseen $^{46}$. Ejemplo de ello fueron las obras mencionadas, aunque en la otra dirección ya mencionada, de Lertora Mendoza y Sanguineti.

\section{Consideraciones Finales}

Después de este breve recorrido, es plausible sostener que una investigación acerca de la ciencia y sus causas se desarrolló confusamente en las décadas del siglo xx. En efecto, los diferentes planos de análisis de esta temática en la doctrina del Aquinate presentan los siguientes inconvenientes:

a) Puede sostenerse, a modo de balance entre los intérpretes tomistas del siglo pasado, que los estudiosos de la epistemología sobre el Aquinate,

44 Gelonch, S., Separatio y Objeto de la Metafísica. Una interpretación textual del Super Boetium de Trinitate, q5 a3, de Tomás de Aquino. Eunsa, Pamplona, 2002. p. 61. Cfr: M. A. Vitoria, «Pasado y Presente de la doctrina de los grados de abstracción. Notas sobre su valor epistemológico», en: Acta del Congresso Tomista Internazionale: L'Umanesimo cristiano nel III milenio: Prospettiva di Tommaso d'Aquino, Roma, 21-25 de settembre, 2003: Con una actitud diferenciante de pensamientos dice: «[...] los autores tomistas quisieron seguir la doctrina del Santo, completando su pensamiento. Pero en este intento adoptaron una terminología no usada por Santo Tomás (grados de abstracción, abstracción total y abstracción formal) que se difundió ampliamente en muchos manuales de lógica neo-escolástica por influjo de Cayetano y de Juan de Santo Tomás, y que dio lugar a malentendidos no sólo terminológicos sino de concepto (p. 7)». "[...] puede decirse que la doctrina tomista de los niveles de intelección proporcionó un marco válido para la distinción y articulación de los saberes, que sigue teniendo validez hoy (p. 7)». Cfr: J. A. García Cuadrado, La luz del intelecto... pp. 218-235: «Tómese como ejemplo un breve estudio de la naturaleza de la abstracción del intelecto agente como diversa de la tomasiana en los casos de Cayetano con su "iluminación objetiva", Silvestre de Ferrara con su "iluminación radical" y Domingo Bañez con su "iluminación efectiva" ».

45 Sirva de ejemplo la síntesis biográfica tomasiana superadora de las deficiencias de otras en, cfr: Torrell, J.-P., Iniciación a Tomás de Aquino: su persona y su obra, Eunsa, España, 2002.

46 No faltan artículos al respecto, pero una visión especulativa en la que se ponderen armónicamente para la noción de ciencia en Tomás de Aquino las expresiones de esse, ens, abstractio, separatum, causa, etc en los tópicos del hombre, los ángeles y Dios y la ciencia como virtud dianoética, don del Espíritu Santo, y sus relaciones con la sabiduría y el intelecto, parece no haberse llevado todavía completamente a cabo. Ejemplos de cierta aproximación al tópico de la ciencia pueden ser las 4 obras de, cfr: ÉchIVARD, J-B., Les proèmes des lectures de saint Thomas d'Aquin aux oeuvres principales d'Aristote. 
al ser herederos de una escolástica moderna, habrían coincidido en el modo de plantear la cuestión de la ciencia en Tomás de Aquino. Vale decir, o bien por estar imbuidos de la filosofía de Cayetano, o bien, por considerar como tópicos de investigación la óptica del de Gaeta aunque desde el mismo Tomás, esto es: la preeminencia de la gnoseología como método explicativo de lo real, justificando principalmente por medio de la abstractio la división especulativa de la ciencia en Tomás de Aquino.

b) Se ha presentado en la historia del tomismo el siguiente movimiento reductivo: dando por probado que las doctrinas neo-escolásticas aparecen mezcladas con aquella del Aquinate, o en donde en el mejor de los casos se haya estudiado la metafísica tomista pura, se descubre que ella gira, se convierte en y reduce a gnoseología como metafísica especial y cuyo epíteto contemporáneo sería la expresión epistemología. En este sentido Tomás no concede subdivisiones a la metafísica y no incluye en la división de las ciencias una gnoseología, aunque sí la lógica, que no es necesariamente idéntica.

c) La separación moderna entre ciencia y filosofía condujo el cultivo de la doctrina tomística a manos principalmente de personalidades alejadas del quehacer concreto de la ciencia, y con ello, según el juicio histórico, una progresiva decadencia. En otras palabras, Tomás de Aquino labró una filosofía del ser de la cual su terminología emergió del pensamiento vivo de la ciencia física, para luego dicho vocabulario, con sus restricciones y acomodamientos, sirviese en la metafísica. En el Aquinate éstas eran claramente dos ciencias, cada una con sus fines y métodos distintos ${ }^{47}$. Para los comentadores modernos la diferencia se tornó cada vez más ficticia o nominal y condujo a la subsunción de la física en la metafísica. Todas las explicaciones de la física eran metafísicas y su falsedad se vio patente en una forma de hacer metafísica sin conocer la misma ciencia física. Por otro lado, la ciencia física se desvinculó de su verdadera génesis y avanzó en una matematización creciente de las sustancias sensibles al punto de concebir, históricamente, una física que tenía dos modos de explicación moderna: 1. Los tomistas distinguían entre la ciencia física al modo aristotélico y una ciencia intermedia físico-matemática. 2. Los científicos se ubicaban sólo en esta última dirección.

En síntesis, este breve recorrido histórico sobre el tomismo continuador de Cayetano invita a la realización de posteriores estudios sobre las diferencias de sentido con Tomás entre las expresiones scientia, abstractio, esse y ens entre otros.

CONICET, Mendoza - Argentina

José María Felipe Mendoza josefelipemendoza@hotmail.com [Artículo aprobado para publicación en diciembre de 2012]

47 Para un estudio del método en Tomas de Aquino, cfr: Elders, L. J., Sobre el método en santo Tomás de Aquino, Sociedad Tomista Argentina, Buenos Aires, 1992. 